\title{
SOLSTÍCIOS E EQUINÓCIOS COMO SOMBRAS DE PRODUÇÃO DA VIDA
}

\author{
Carlitos Luís Sitoie ${ }^{1}$
}

Resumo: As sombras representam assuntos culturais, econômicos e políticos do cotidiano. Na cidade de Macapá (BR) e no povoado de Aqui (MZ), os equinócios e solstícios, simbolizam sobreposição de sombras, assim como, as mudanças de estações do ano que subsidiam festividades por esses acontecimentos. As sombras frequentemente são entendidas como lugares escuros que se relacionam ao sombrio, entendidas como sítios de medo, estranheza, assustador e pouco se revelam as suas potencialidades na vida cotidiana. $\mathrm{O}$ artigo procura trazer a categoria sombra e suas contribuições em diferentes esferas da vida sociocultural, econômica e política. O estudo de caso foi baseado nos moradores do povoado de Aqui no distrito de Massinga em Moçambique (MZ) e da cidade de Macapá no Estado do Amapá no Brasil (BR). Os resultados da pesquisa mostram que as sombras são aproveitadas pelos moradores do povoado de Aqui para agricultura na produção de cultivares de baixo fotoperiodismo, na caça para identificação de abrigos/esconderijo de animais, na pesca para situar cardumes de peixe, determinação de distâncias a partir de numeração de sombras ao longo do percurso, traçado de rumos e azimutes nas trilhas de caminhadas, produção de calendários anuais baseados em ciclos naturais das sombras, na criação de ovíparos para selecionar o número de machos ou fêmeas, sendo que os ovos em sombras dará origem machos, elaboração de calendário anual, entre outros. Já em Macapá, são usadas as sombras na ventilação de habitações entre outras infraestruturas, sombreamento de calçadas e praças públicas, na produção animal são utilizadas para melhorar a qualidade da carne e na educação estão inseridos em conteúdos programáticos de ensino da Geografia sob alcunha de equinócios.

Palavras-chaves: Sombra. Equinócios e solstícios. Aplicação das sombras.

\section{SOLSTICES AND EQUINOXES AS SHADOWS OF LIFE PRODUCTION}

\begin{abstract}
The shadows represent Cultural Affairs, economic development and politics of everyday life. In the city of Macapá (BR) and here in town (MZ), the equinoxes and solstices, symbolize overlapping shadows, as well as the changes of seasons that subsidize festivities for these events. The shadows are often construed as dark places that relate to dark, understood as places of fear, awkwardness, strangeness, scary and little reveal their potential in everyday life. The article seeks to bring the shadow and category and his contributions in different spheres of socio-cultural, economic and political life. The case study was based on the residents of the village of Here in the District of Massinga on Mozambique (MZ) and the city of Macapá in the State of Amapá in Brazil (BR). The survey results show that the shadows are used by residents of the village of Here for agriculture in the production of plant varieties low photoperiodism, in the hunt for the identification of shelters/animal hideouts, fishing to locate shoals of fish determination of distances from in the shadows along the route, and the azimuth direction path walking trails, production of annual calendars based on natural cycles of shadows, in the creation of oviparous to select the number of males or females,
\end{abstract}

\footnotetext{
${ }^{1}$ Universidade Federal do Amazonas. Email: carlitossitoie@yahoo.com.br
} 
being that the eggs in shadows will lead males, preparation of annual calendar, among others. Already in Macapá, the shadows are used in the ventilation of rooms between infrastructure, shading sidewalks and public squares in animal production are used to improve the quality of meat and in education are inserted into the syllabus of Geography education under nickname of equinoxes.

Keywords: Shadow. Equinoxes and solstices. Application of the shadows.

\section{SOLSTÍCIOS Y EQUINOCIOS COMO SOMBRAS DE PRODUCCIÓN DE LA VIDA}

Resumen: Las sombras representan asuntos culturales, económicos y políticos del día a día. En la ciudad de Macapá (BR) y en el pueblo de Aqui (MZ), los equinoccios y solsticios, simbolizan la superposición de sombras, como también, los cambios de estación durante el año que favorecen festividades por tales acontecimientos. Las sombras frecuentemente son entendidas como lugares oscuros que se relacionan con lo sombrío, son vistas como sitios de miedo, extrañeza, de susto y poco se revelan sus potencialidades en la vida cotidiana. El artículo procura traer la categoría sombra y sus contribuciones en diferentes esferas de la vida sociocultural, económica y política. El estudio de caso fue basado en los habitantes del pueblo de Aqui en el distrito de Massinga en Mozambique (MZ) y de la ciudad de Macapá en el Estado de Amapá en Brasil (BR). Los resultados de la investigación muestran que las sombras son aprovechadas por los moradores del pueblo de Aqui para agricultura, en la producción de cultivos de bajo fotoperiodismo; en la caza, para identificación de refugios/escondrijos de animales; en la pesca, para situar cardúmenes de peces; en la determinación de distancias a partir de la numeración de sombras a lo largo del recorrido, en el trazado de rumbos y acimuts en los caminos para andar; en la producción de calendarios anuales basados en ciclos naturales de las sombras; en la producción de ovíparos para seleccionar el número de machos o féminas, teniendo en cuenta que los huevos en sombras darán origen a machos; en la elaboración del calendario anual, entre otros. De otro lado, en Macapá las sombras son usadas en la ventilación de habitaciones y otras infraestructuras; en el sombreado de calzadas y plazas públicas; en la producción animal, son utilizadas para mejorar la calidad de la carne y en la educación están incluidas en los contenidos programáticos de enseñanza de Geografía bajo el alias de equinoccios.

Palabras clave: Sombra. Equinoccios y solsticios. Aplicación de las sombras.

\section{Introdução}

A palavra sombra é constituída de abstrações que permitem reconhecer objetos e coisas por meio de conceituações, teorizações e produção de sinapses que possibilitam mesmo ausentes os objetos e coisas, a sua identificação por meio de códigos de linguagem.

Os conhecimentos sobre o comportamento das sombras visualizam momentos de mudanças de estações do ano (solstícios e equinócios) no instante em que as sombras se 
sobrepõem aos objetos que as projetam. Permite compreender, também, definição de sexo em repteis, os planejamentos na saúde pública, agricultura, pecuária, urbanismo, marcação de calendários para festividades, sendo abrigos de animais e lugares ideais para “[...] caçar, procurar frutas ou nozes e raízes [...] (MILONE, 2003, p. 9)”.

Muitas escolas africanas servem-se das sombras como lugares de estudos, tornando importante conhecer suas trajetórias ao longo do ano, para permitir saber a posição ideal de onde colocar, por exemplo, uma "sala-sombra" ${ }^{2}$ " de aulas em determinado horário do dia e época de ano.

Baseando-se em Tuan (1980) pode-se dizer que a sombra é um fenômeno culturalmente representativo de espaço geográfico, que a partir dela os moradores do povoado de Aqui e da cidade de Macapá produzem saberes configurativos do espaço vivido, mental e concebido, quer dizer, esse fenômeno simbolicamente representa assuntos culturais, econômicos e políticos do cotidiano.

Apoiando-se em Milone (2003, p. 9), Tuan (1980), Head (1995), Carvalho et. al. (2002) e Dias-Filho (2006), pode-se dizer que a sombra influencia na determinação sexual de repteis, cágados e tartarugas. Quer dizer, o sombreamento principalmente nas margens de rios e no litoral, serve para desova dos repteis, diminuindo a temperatura média da areia e quanto mais baixas forem as temperaturas da areia, aumentará o nascimento de filhotes machos, o que pode ser usado para gerar equilíbrios ou desiquilíbrios entre as populações de machos e fêmeas. As sombras são também usadas em projetos de engenharia civil para amenizar as altas temperaturas nos espaços urbanos e rurais, ventilação para animais e plantas entre outras atividades relacionadas à compensação das amplitudes térmicas diurnas.

O controle de equinócios e solstícios por meio da sombra, sempre foi alvo de observação humana, por isso Milone (2003, p. 9) afirma que os povos da antiguidade oriental (caldeus, fenícios, incas, astecas e egípcios), faziam festas para comemorar a "[...] data em que o dia vencia as trevas [...]”, dia 21/22 de dezembro, correspondente ao solstício de verão. A data de solstício de inverno, com a emergência do cristianismo foi decretada pelo Papa Júlio I em 350 d.C. em festa junina, já o solstício de verão, reservado ao nascimento do menino Jesus Cristo, que passou a ser comemorada no dia 25 de dezembro.

$\mathrm{O}$ artigo foi estruturada em cinco subtemas principais, com vistas a explicitar de forma

\footnotetext{
${ }^{2}$ Denominação de sombra de árvores usadas como salas de aulas para estudar
} 
profícua os elementos de cunho analítico. Nessa analise foram abordados assuntos relacionados com os solstícios e equinócios sob categoria de sombras, incluindo aspetos simbólicos em que as sombra são utilizados na construção de conhecimentos. Assim como valor socioambiental dos cemitérios por meio das sombras, a influência das sombras para a saúde humana, a sombra na agropecuária, as considerações finais e finalmente apresentadas referências bibliográficas que serviram de suporte teórico e metodológico para análise ao trabalho de investigação.

\section{Metodologia}

Para o estudo foram escolhidas duas cidades atravessadas pela linha imaginaria do Equador e Trópico de Capricórnio. Sob a linha do Equador elegeu-se a cidade de Macapá, conotada cidade no meio do mundo devido a localização estratégica, desenhando um perímetro urbano correspondente as seguintes coordenadas geográficas $00^{\circ} 8^{\prime} 37^{\prime \prime} \mathrm{S} ; 5^{\circ} 16^{\prime} 18$ 33" W; 00 10' 9" N e 5056'45"W, às margens do rio Amazonas (MAPA 1).

Mapa 1 - Situação geográfica de Macapá - AP.

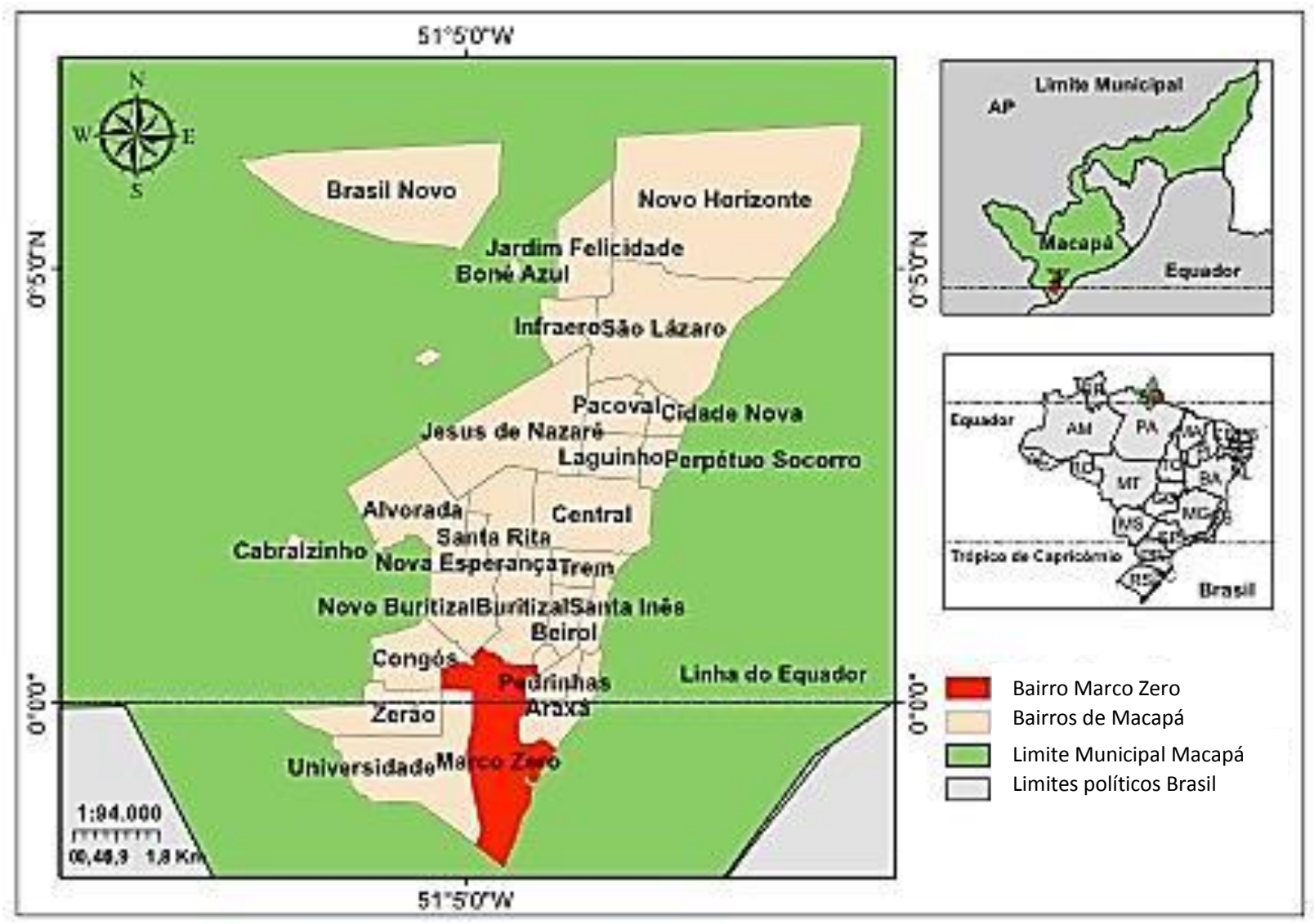

FONTE: Elaborado por Carlitos Sitoie com recurso ao QGIS 2.18.15 'las Palmas', para tese de Doutorado. 
O povoado de Macapá foi escolhido para a pesquisa por localizar-se numa latitude onde durante o seu movimento aparente, o sol retorna ao norte quando atinge sua mobilidade máxima ao sul sobre a linha imaginária do Trópico de Capricórnio (T.CAP), no instante que está incidindo seus raios numa inclinação de quarenta e seis graus e cinquenta e quatro minutos (465') sobre o povoado de Aqui e outros lugares atravessados por essa linha.

Geograficamente, o povoado fica situado na província de Inhambane, distrito de Massinga em Moçambique (MAPA 2). Ao sul delimita-se pelo povoado de Licunha, ao Norte por Malova, a Leste pelo povoado de Chissindane e Oeste por Cangela, numa área de aproximadamente quarenta quilômetros quadrados $\left(40 \mathrm{~km}^{2}\right)$ de extensão territorial. A sede do povoado está situada na coordenada astronômica, vinte três graus, vinte seis minutos, vinte dois segundos $\left(23^{\circ} 26^{\prime} 22^{\prime \prime} \mathrm{S}\right)$ Sul e trinta e cinco graus, cinquenta e dois minutos, vinte e dois vírgula dois segundos $\left(35^{\circ} 52^{\prime} 22,2^{\prime \prime} \mathrm{E}\right)$ Leste.

Mapa 2 - Localização geográfica do Povoado de Aqui - Moçambique.

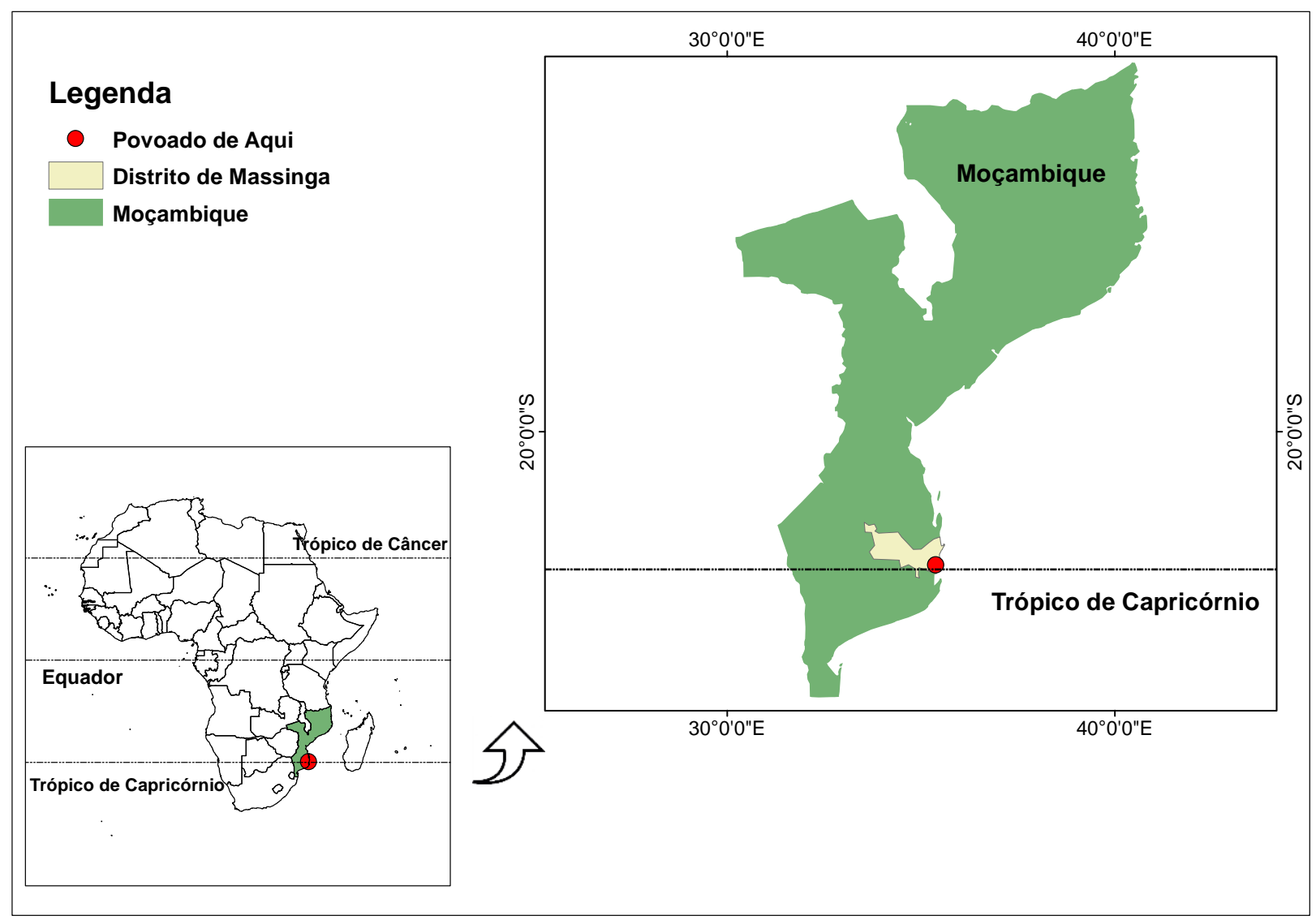

FONTE: Elaborado por Carlitos Sitoie com recurso ao QGIS 2.18.15 las palmas, para tese de doutorado. 
Para operacionalização do estudo recorreu-se à revisão bibliográfica e trabalho de campo, numa abordagem teórica conjugada entre o paradigma ecológico do pensamento antropológico de Ingold com as observações e entrevistas aos sujeitos sociais. Em Macapá, as entrevistas foram feitas durante os equinócios envolvendo os moradores participantes no ritual de passagem do sol pelo obelisco do monumento Marco Zero.

\section{Sombra e construção de conhecimentos}

As sombras jamais gozaram de boa reputação devido à falta de luz, sendo associadas a coisas incertas, estranhas, envoltas nas suspeitas, entendidas como má companhia, por isso, associadas ao que assusta. Aquilo que é inferior e perigoso, o que engana, entristece e ameaça. Foram sempre entendidas como fenômenos inquietantes, esquisitos que: crescem e diminuem, aparecem e desaparecem que estão presas ao corpo, mas não há como capturá-las (CASATI, 2001, p.117).

O mesmo autor afirma que apesar de compreendidas como negativas desempenharam um papel crucial na construção de conhecimentos científicos. Foi na base das sombras que Eratóstenes (276-194 a. C.) determinou o tamanho da Terra deduzindo que a sua forma era esférica ao observar a sombra de dois objetos situados em lugares distantes (COSTA, 1999). Em Assuão antiga Siene e Alexandria no Egito atravessados pela linha imaginária do Trópico de câncer, durante o solstício de junho ou de inverno, ao meio-dia solar local, constataram que as sombras se sobrepunham aos objetos que as projetam.

O pensamento de Eratóstenes não norteou apenas conhecimentos que permitiram a determinação da forma e dimensão da terra, mas também estudos dos eclipses, estabelecimento de distâncias entre a terra, lua e sol, descobrimento de estrutura do sistema solar e das órbitas dos planetas. Permitiu ao Galileu a dedução do relevo de outros planetas e da lua, inventar a perspectiva linear e compreender as projeções matemáticas.

A sombra torna-se “[...] amiga do conhecimento, agregando um clube de sócios das sombras [...]" (CASATI, 2001, p.17), que aglutina pensadores da antiguidade, da idade média e do renascimento como é o caso de Galileu Galilei (1564-1642) e Ptolomeu (90-168), cujas redescobertas renascem com as pinturas de Leonardo da Vinci (1452-1519), impulsionando dois grandes avanços do mundo ocidental, criando a perspectiva geométrica que permite inserir objetos no espaço durante o desenho ou pintura. 
A sombra passou a ser importante para leitura do fundo e perspectivas de uma imagem, dando relevo as imagens como é o caso de maquiar o rosto que precisa aumentar a sombra para dar maior profundidade ao rosto. Na idade moderna, popularizaram-se estudos científicos relacionados com a teoria das sombras, sombrografia ${ }^{3}$ e aperfeiçoamento de relógio solar útil para planejar atividades diárias, tudo isso baseados em conhecimentos sobre as sombras.

No planejamento urbano passaram a desempenhar papel importante, por se revelarem essenciais na orientação de moradias e arruamentos da cidade, evitando obstrução do céu ou tornar a cidade excessivamente escura pela deficiente insolação. Na cidade de Nova York a construção de arranha-céus como Manhattan, com sombras gigantes dificultam a insolação por todo o quarteirão. Tornando crucial o planejamento urbanístico por meio das leituras e interpretações de trajetórias que as sombras realizam ao longo do dia numa determinada área geográfica, isto é, os construtores de uma cidade devem ter o domínio do "[...] regulamento anti-sombra [...]" (CASATI, 2001, p. 28).

Na Idade Média, Al-Burini escreveu um livro denominado 'Tratado completo das sombras' entre 1030-1040. Determinando o momento em que a sombra é igual ao dobro e metade das coisas como horários para recitar preces islâmicas, neste caso, a sombra das coisas e objetos constitui relógio solar para determinar o horário em que os mulçumanos deveriam recitar suas orações ao longo do dia.

Filósofos e renascentistas usaram o conceito de sombra para analogicamente significar dois movimentos do pensamento: a sabedoria e a ignorância. No livro a República, Platão (427-347a.C.) (2001) impulsiona a capacidade de abstração, partindo da alegoria da caverna, comparando a condição de ignorância como uma sombra ou escuridão e a de raciocinar para atingir a sabedoria como o momento do iluminismo ${ }^{4}$. Congregando pensadores como René Descartes (1596-1650) precursor da dúvida metódica, John Locke (1999b) do empirismo, Voltaire (1694-1778) defensor da liberdade de pensamento, Rousseou (1712-1778) que escreveu sobre a democracia e igualdades, Montesquieu (1689-1755) que instituiu por meio

\footnotetext{
${ }^{3}$ Técnica direta de exposição de objetos sobre papel fotossensível.

${ }^{4}$ Movimento intelectual com origem na França defendia a capacidade humana de conhecer o mundo por meio da ciência, considerada expressão de rigor, objetividade e previsibilidade. Exaltava que, pela ciência o homem podia espantar o medo causado pelas sombras, ignorância e superstição, guardando a esperança de um mundo onde as luzes da razão permitiriam a melhor qualidade de vida possível e a emancipação dos preconceitos, da violência e do arbítrio. De acordo com os filósofos iluministas, esta forma de pensamento tinha o propósito de jogar luzes nas trevas em que se encontrava grande parte da humanidade.
} 
do seu livro a necessidade da divisão de poderes em qualquer Estado. A preocupação destes pensadores era impulsionar as mentes de forma a saírem do mundo das sombras para o mundo das luzes. Por meio de teorias que iluminassem os europeus, em particular, os franceses abalados pelas contradições do antigo regime sob jugo de um sistema fundiário moroso, de caráter aguçado, que gerava insatisfação nos diversos setores da sociedade, especialmente entre a burguesia e os pequenos camponeses.

Atualmente a psicologia cognitiva, a astrologia e a filosofia da ciência se valem por meio da análise das sombras para seu objeto de estudos. Psicologicamente, a sombra é o interior do indivíduo caracterizado por experiências não desejáveis “[...] portanto, a única forma de conhecer esse lado e ajudá-lo a curar-se é conhecer a sombra [...]." (SALETE, 2009, p.138). Para o psicanalista Car Gustav Jung (1875-1961) (2011) a sombra é o arquétipo do ego do indivíduo e mais sombrio, ou seja, a sombra constitui a parte animalesca da personalidade humana, herdado das formas inferiores de vida desde quando éramos selvagens até atingir o estágio atual. As sombras em psicanálise são representantes primordiais das coisas físicas, visualizadas na realidade como “[...] imagens da alma [...].” (CASATI, 2001, p.46)

De acordo com Tuan (1980) e Chopra et al., (2010), elas podem representar também aspectos sombrios como o medo, a raiva, a ansiedade e a violência, entre outras possessões demoníacas, cuja solução é purificar a pessoa acometida por meio de rituais, limpeza do corpo, jejum e austeridades exaustivas. Na Amazônia brasileira, existe uma prática espiritual que procura ler e interpretar a parte sombria do indivíduo através do ayahuasca.

A [...] possibilidade da utilização da bebida Ayahuasca dentro de um ritual apropriado, funcionando como um agente terapêutico, onde através de sua ingestão abre-se a possibilidade de acessar conteúdos internos que são tratados como sombras, gerando progresso físico mental e emocional do bebedor (MEDEIROS, 2016).

Segundo Almeida (2016) e Axt (2007), em física, elas representam fenômenos da óptica geométrica, evidenciando a propagação retilínea da luz e ar, tendo como consequência a formação de sombra, que se dá quando a luz encontra em seu caminho um objeto opaco (todo objeto que não permite a propagação da luz através de si). Neste caso, a sombra resulta de uma "[...] deficiência local e relativa da quantidade de luz visível [...]" (BAXANDALL, 1997, p.17), sendo que a luz depende da variação da sombra para iluminar, tornando-se elemento essencial para que haja luz. 
A luz é a quantidade do fluxo da unidade de massa-energia emitida por uma fonte de radiação, pelo sol ou por uma vela, mas é a sombra que dá volume e autenticidade permitindo visualização de imagens, portanto, são dois fenômenos físicos que se complementam, assim nenhum existe sem o outro. Portanto, a sombra é um fenômeno que dá existência a luz e a luz que dá origem a sombra.

As sombras constituem a prova da “[...] manifestação divina e são mentalmente imortais, servindo também na ligação dos homens com Deus [...] guardando a essência da existência humana [...]” (SANTO AGOSTINHO, 354-430; SÃO TOMÁS DE AQUINO) (TOMÁS DE AQUINO, 1979). As sombras são representações projetadas dos vegetais, animais, seres humanos, de todas as coisas e objetos, portanto, a alma dessas coisas e objetos que as projeta.

Ao atribuir o papel de alma ascende à categoria de imortalidade, sendo que representam fisicamente e visivelmente a "[...] alma das coisas [...]" (CASATI, 2001, p.36), desempenhando dinâmica vital.

A alternância entre claridade ou luz e escuridão, noite, constitui elemento primordial para a construção de um conceito vital denominado dia equivalente à vinte e quatro (24) horas ou a "[...] primeira noção do tempo [...]" (MILONE, 2003, p.16) neste caso, a escuridão é a sombra que simboliza nos ciclos vitais, o período noturno e de sono, hibernação, descanso, recarga de energia perdida durante a claridade solar enquanto que a luz solar ao tempo de vigília, da irradiação solar necessária para a fotossíntese, distribuição de sais minerais e energia para plantas e animais.

Quando entendidas como alma das coisas e objetos, atribui-se às sombras além do movimento, mas também, um lugar transcendental no topo da hierarquia vital, como a imortalidade ou continuidade da vida pós-morte.

Teologicamente, a sombra representa o Senhor Todo Poderoso, o criador de todas as coisas visíveis e invisíveis (Deus), em Gênese, 1:2 quando da formação da terra, é relatado que a terra estava vazia e vaga com as trevas cobrindo o abismo, esse abismo é a sombra. Que atribui-se poderes mágicos por meio da cura aos aleijados ao tocar na milagrosa sombra do São Pedro. Na Bíblia (1980) cita-se o relógio solar de Acaz. Em $2^{\circ}$ Reis capitulo 20:8-11 e em Isaias 38.8, quando Ezequias disse a Isaías: Qual é o sinal de que o senhor lhe sarará, e de que ao terceiro dia subirá à casa do senhor? Isaías respondeu que: Adiantar-se-á a sombra dez graus, ou voltará dez graus atrás. Neste âmbito, a sombra simboliza um ser vivo, 
especialmente humano muito poderoso que cura doenças e ajuda na dinâmica vital de todos seres vivos e não vivos. Na mesma altura, a sombra representa espaço geográfico construído pelo "[...] onipotente, correspondente ao sistema ambiental religioso, com a presença do senhor, a sombra representando inferno, trevas, o lugar obscuro, perigoso enquanto que a luz ao paraíso e a felicidade eterna" (GÊNESIS 1:4).

O coreógrafo Lin Hwai-Min e o artista chinês Cai Guo-Qiang, criaram uma obra de dança contemporânea denominada dança das sombras ou "Wind Shadow", onde as sombras ganham vida, movimentando-se por meio do uso de paletas monocromáticas pretas e brancas e do contraste entre a luz e a sombra, dando vida aos bonecos com efeitos sonoros e de luz, criando impressão de que são humanos contando suas histórias de vida.

Na cidade de Macapá, em Amapá (BR) e no povoado de Aqui em Moçambique, os moradores fazem sombreamento em cemitérios, na crença de que a sepultura precisa ser conservada em um ambiente confortável porque preserva o corpo físico do falecido e a sua alma precisa de tranquilidade e paz. Esta crença agrega ao cemitério a categoria de última moradia ou casa eterna de seres humanos representados pela alma que é a sombra do falecido.

\section{O valor socioambiental dos cemitérios por meio das sombras}

Para Vovelle (1993), os cemitérios são ambientes de repouso privilegiado, sítios agrestes repletos de monumentos aptos a acolher todas as homenagens da memória familiar e do respeito cívico, tornando os túmulos "[...] vasto campo para estudos da arqueologia, da etnologia, da história, das artes e da filosofia.” (VIOLLET-LE-DUC, 1867-1870). Nessa perspectiva o cemitério é a segunda residência de quêm faleceu, onde o túmulo é a casa, repleto de elementos arquitetônicos e paisagísticos presentes do cotidiano ou do mundo dos vivos "[...] é ali onde se reproduz de fato ou de forma idealizada, a ordem socioeconômica dos vivos.” (RAGON, 1981, p.37). Transformando os cemitérios em patrimônios socioambientais embrenhado de símbolos e valores que darão significação à vida.

Esse valor socioambiental, está relacionado com o fato de que os cemitérios representam áreas de sombreamento através de toldos ou coberturas para túmulos e arbóreo ou verde, por se tratarem de lugares da morada permanente dos mortos e usados pelos vivos para comungar com os espíritos ou almas dos ancestrais. Conforme enfatizou um morador da cidade de Macapá: 
[...] a igreja ensinou-me que os mortos não estão mortos, eles estão vivos, com uma outra vida, isso está escrito no livro Sabedoria capítulo dois (2), versículo vinte três (Sb 2:23) da Bíblia Sagrada; é por isso, que temos a obrigação de colocar nossos falecidos num lugar confortável com uma sombra boa, fazer limpeza, cuidar [...] (informação verbal) ${ }^{5}$

Analisando a colocação de Sabedoria (2:23) é possível afirmar que a ideia de cuidar dos túmulos dos falecidos, busca sua inspiração no catecismo da igreja católica, que ensina aos crentes, que todos os que morrem na graça e na amizade de Deus, nem sempre estão completamente purificados, embora tenham garantida a sua salvação eterna, portanto, passarão após sua morte, por uma purificação, afim de obterem a santidade necessária para entrarem na alegria do Céu, assim, sombrear e dar outros cuidados aos túmulos cria alegria e ambiente agradável ao falecido.

Além das sombras serem confortáveis para o falecido, existe a crença de que o indivíduo quando morre santifica-se, podendo controlar ou realizar milagres na vida de seus familiares que estão ainda vivos criando ambientes confortáveis nos túmulos de seus familiares falecidos no sentido de obter alguma graça.

O sombreamento em cemitérios constitui um dos itens prioritário no planejamento socioambiental, porque esses lugares “[...] constituem o patrimônio cultural e espaços muito frequentados, constituindo pontos turísticos consolidados nos mais diferentes países do mundo [...]" conforme Viollet-le-Duc Vovelle (1993), Ragon (1981, p.37), Mumford (1991, p. 13), Osman e Ribeiro (2007, p. 3). Atraindo visitantes de toda parte interessados em conhecer túmulos de personalidades das diferentes áreas do conhecimento, apreciar obras de arte que ornamentam os túmulos ou simplesmente desfrutar de momentos de paz e tranquilidade nos jardins arborizados tornando esses espaços em “[...] cemitério-jardim, aberto ao publico" (CHARLET, 2003).

Osman e Ribeiro (2007) citam alguns exemplos de boa estrutura de cemitérios com sombreamentos, criando ambiente confortável para os visitantes no Brasil, assim como, na rota turística pelo mundo, começando pelos franceses, do Père Lachaise, de Montparnasse e de Montmartre, seguidos pelos cemitérios ingleses: Highgate e Golders Green Crematorium, em Londres. Na América do Sul lidera o cemitério da Recoleta, em Buenos Aires, seguido dos cemitérios brasileiros, da Consolação e do Morumbi, em São Paulo, São João Baptista, no Rio de Janeiro.

${ }^{5}$ Sujeito G.M., 48 anos de idade (cidadão comum, cidade de Macapá). 
Outro exemplo brasileiro é o ambiente confortável produzido a partir de sombreamento arbóreo no Cemitério do Imigrante constituindo “[...] um dos poucos cemitérios brasileiros erigidos no paisagismo de um bosque, conservando e cultivando árvores frondosas selecionando plantas decorativas regionais [...]" (VALLADARES, 1972, p. 310). Esses lugares são ambientes de tranquilidade, repouso e resgate cultural propiciado pelo sombreamento e espaços verdes que representam encontro com aquilo que é natural, com ancestralidade, simbolizando a primavera, juventude e paixão, fertilidade, desenvolvimento, riqueza, boa sorte, esperança, ambientes mais fresquinhos.

Por ser prioridade na atualidade, transformar os cemitérios em ambientes fresquinhos e agradáveis, fez com que surgissem projetos planejam cemitérios sustentáveis, a destacar o projeto Capsula Mundi na Itália, que consiste no enterro de falecidos em uma:

[...] cápsula orgânica e biodegradável com formato de um ovo contendo raízes de uma muda ou sementes que é capaz de transformar um corpo em decomposição em nutrientes para uma árvore que transformará os cemitérios em florestas ou espaços de sombreamento sagrado (TREES..., [2016?]).

Experiências parecidas estão sendo desenvolvidas no Brasil, como é o caso do bosque ou cemitério Horto da Paz em São Paulo com um pequeno bosque que recebeu o nome Paz e Vida conta com pelo menos 300 árvores que os familiares plantam no momento em que deixam as cinzas do falecido junto às mudas. Os familiares que optam pela cremação adquirem urna cápsula ecológica, feita de fibras de coco totalmente biodegradável, que é acompanhada de sementes ou uma muda de árvore a ser plantada junto com as cinzas e assim formar uma floresta que projeta sombras sagradas. Além do sombreamento arbóreo, existem telas protetoras de calor nas sepulturas como é o caso do cemitério Nossa Senhora de Conceição de Macapá.

Em Macapá a cobertura superior de túmulos é feita obedecendo a uma técnica que a sombra esteja sobreposta durante todo o ano na hora mais quente do dia. Geralmente são os familiares do falecido que mandam construir a tela de proteção solar, fazem limpezas frequentes aproveitando a sombra durante as visitas ao lugar.

\section{Influência das sombras para a saúde humana}

A radiação solar e sombreamento desempenham um papel importante na manutenção 
física e sanitária dos seres vivos e em particular do Homem. Os raios solares são importantes para a vida na medida em que oferecem vitaminas ao organismo, mas também podem causar doenças quando recebido em excessos. A cidade de Macapá e o povoado de Aqui, que apresentam amplitudes térmicas, oscilando por volta dos $27^{\circ} \mathrm{c}$, vão receber ao longo do ano uma insolação que varia entre 114 a 285 horas, durante os equinócios e solstícios. Isso vai fazer com que esses dois lugares recebam uma intensa radiação solar, havendo maior probabilidade de exposição dos seus moradores à exposição de doenças relacionadas ao sol intenso, podendo atingir situação de estresse, reduzindo seu desempenho nas atividades cotidianas principalmente quando o organismo recebe insolação intensa na hora mais quente do dia cerca das $11 \mathrm{~h} 30 \mathrm{~min}$ até às $15 \mathrm{~h} 30 \mathrm{~min}$ local.

Durante o nascente e poente solar, as temperaturas são amenas, acelerando a fixação de vitamina $\mathrm{D}$ no corpo humano, que contribui na diminuição da incidência de depressão entre outras doenças do aparelho psíquico, especialmente em idosos, crianças e nos prisioneiros que muitas vezes ficam fechadas em residências sem acesso ao sol nas horas boas para aproveita-lo.

De acordo com Pereira (2003) e Popim et al. (2008), a vitamina D é uma substância essencial para boa função celular reguladora de problemas de insônia, mau humor e depressão ou fadiga crônica. A exposição quando feita na hora mais quente do dia constitui riscos sob raios ultravioletas (RUV) prejudiciais ao ser humano, sendo responsáveis por doenças da pele e psíquicas.

Dentre diversas doenças influenciadas por carência de sombreamento, Popim et al. (2008), Miot et. al. (2009) e Hayashide et al. (2010), destacam a ocorrência de queimaduras solares ou eritema, principalmente em crianças e pessoas de pele clara. Referem-se ainda, ao envelhecimento precoce caracterizado por aparecimento de rugas e manchas na pele também conhecidas como foto envelhecimento, em especial na pele clara.

Os mesmos autores afirmam que, a exposição excessiva em lugares de maior insolação pode também causar problemas de visão devido a queimaduras na córnea, provocando catarata, pterígio e até câncer de pele nas pálpebras, herpes, acne (queimadura e vermelhidão), alergias da pele, melasmas (manchas de cor marrom que aparecem geralmente nas mãos, braços e rosto), queratose (feridas ásperas e pequenas que dificilmente saram), câncer de pele, entre outros transtornos dermatológicos que têm como fator desencadeante os raios ultravioletas. 


\section{Sombra na agropecuária}

Para Stafford-Smith et al. (1985), Belchior (2014), o sombreamento por meio das árvores reduz cerca de 55\% de radiações ultravioletas e $85 \%$ da luz visível contribuindo para o decréscimo de problemas de saúde reduzindo o aquecimento corporal facilitando a termo regulação. Para além da termo regulação as sombras melhoram na agricultura, atividade biológica e fertilidade do solo, principalmente se a árvore for associada a microrganismos que fixam nitrogênio do ar, de acordo com Carvalho et al. (2002) e Lin et al. (2001).

Os sombreamentos para agricultura dividem-se em dois tipos principais: natural, baseado em aproveitamento de sombras projetadas pelas árvores de tamanho maior que as hortaliças, exigindo domínio do caminho das sombras na hora mais quente, enquanto que os artificiais são formados por telas de proteção solar.

De acordo com Primavesi (2006a), sombrear melhora a qualidade nutricional de leguminosas de curto fotoperiodismo, quando produzidas em regiões de clima equatorial quente, como é o caso da cidade de Macapá, recomenda-se a sua plantação sob as sombras para aproveitar as três (3) ou quatro (4) horas por dia, que precisam para ganhar nutrientes e sais minerais.

As plantas de crescimento rápido podem ser produzidas em sombreamento provisório, projetado a partir das plantas de crescimento rápido, tais como: bananeiras e mamoeiros, visando uma proteção imediata ou produzida sobre a sombra de árvores permanente e crescimento lento como é o caso do cajueiro, mafureira, mangueira, coqueiro, entre outras.

$\mathrm{Na}$ falta de árvores, recomenda-se o sombreamento com telas em que as variações na sua produção depende das propriedades artificiais do material que produz sombras, por isso Primavesi (2006b) orienta para uso de telas artificiais diferenciadas (FOTO 1). 
Foto 1 - Ensombreamento através de telas artificiais ExpoFeira do Macapá.

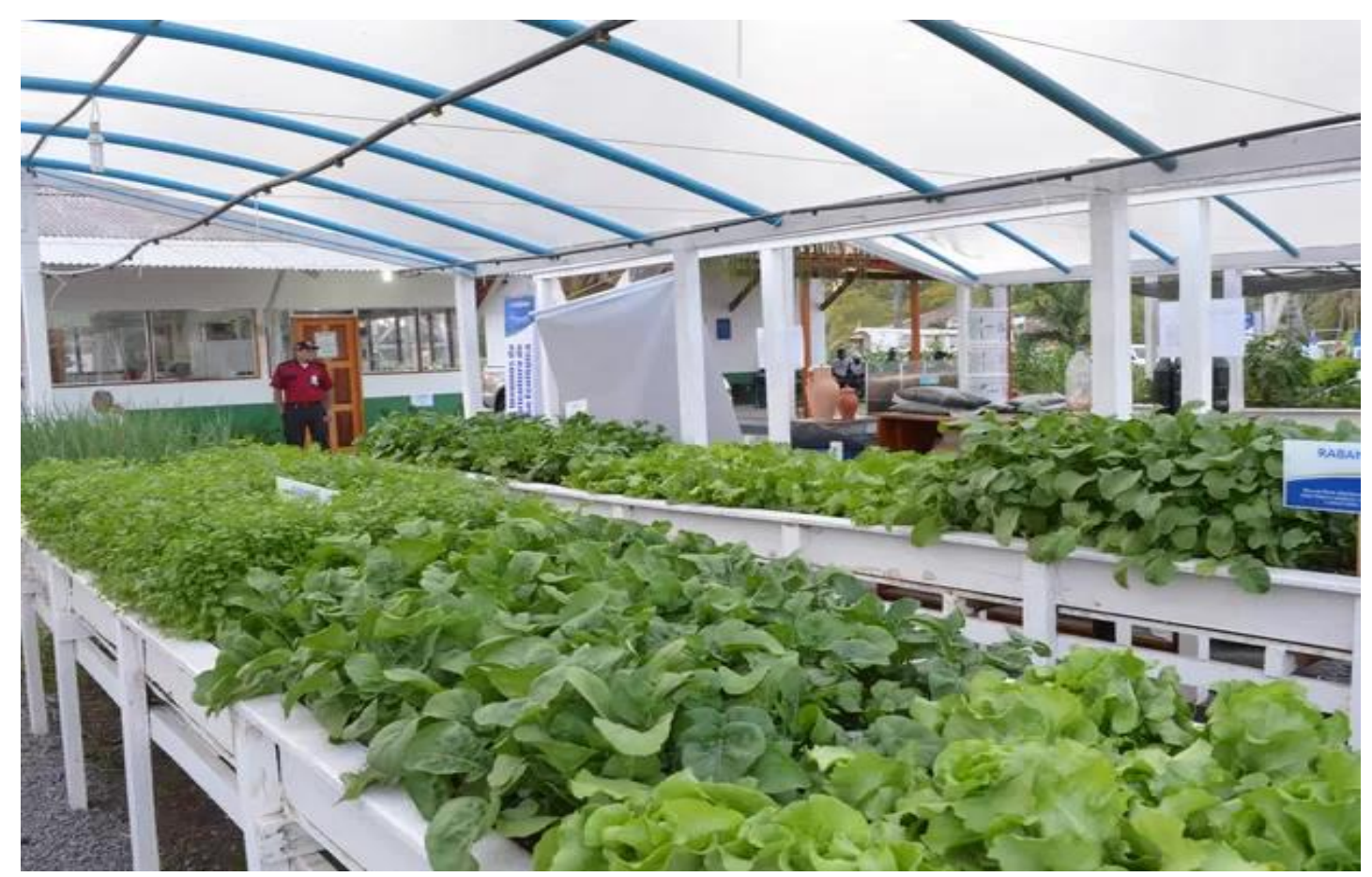

FOTO: Jéssica Alves/G1

Para além da produção agrícola, as sombras constituem lugares ideais para conservação de hortaliças, que mesmo após a colheita, mantêm uma acelerada atividade metabólica, a exposição ao sol mesmo que seja em períodos curtos, acelera a desidratação e deterioração tornando-as suscetíveis à putrefação e menos adequadas para o consumo, recomendando-se para conservação a criação de Unidades Móveis de Sombreamento (UMS).

Para Head (1995), na pecuária intensiva e extensiva as sombras garantem o bem-estar durante períodos de alta incidência de raios solares, diminuindo a temperatura do ambiente e influenciando na diminuição da temperatura do animal que estiver sob ela, ocasionando aumento na ingestão de alimentos e água ao animal incluindo benefícios ambientais.

Barion et al. (2012) recomenda para uso de sombreamento artificial por meio de telas, em situações da ausência de árvores na pastagem ou enquanto se espera o crescimento delas.

Tanto os animais criados em um, assim como no outro sistema, precisam de sombras para manter a homeostasia ou equilíbrio térmico do organismo, sendo que em Macapá prevalece o sistema intensivo praticado pelos fazendeiros, já no povoado de Aqui, o extensivo sobre o trópico de capricórnio. 


\section{Considerações finais}

As sombras permitem conceituações, teorizações e construções de categorias acadêmicas na medida em que constituem imagens do real. Além de que quando entendidas como fenômenos físicos resultantes da obstrução solar, elas servem para visualizar momentos de solstícios e equinócios.

Em diversas sociedades inclusive no povoado de Aqui, são aproveitadas como salassombras de aulas, como lugares para realização de eventos de lazer, rituais tradicionais e locais para desova de repteis e aves, influenciando na definição de machos ou fêmeas. Dinamizam turismo inclusive em cemitérios, são importantes na saúde para regulação de vitamina $\mathrm{D}$ evitando doenças, por isso recomendadas como matérias de ensino agropecuária, construção civil e na medicina.

\section{REFERÊNCIAS}

ALMEIDA, Voltaire de Oliveira. Mapas conceituais como instrumentos potencialmente facilitadores da aprendizagem significativa de conceitos da óptica física. 2006. $232 \mathrm{f}$. Dissertação (Mestrado em Física) - Universidade Federal do Rio Grande do Sul, Porto Alegre, 2006. Disponível em: <http://www.lume.ufrgs.br/handle/10183/11794 >. Acesso em: 08 mar. 2016.

AXT, Rolando; SILVEIRA, Fernando Lang da. Um intrigante fenômeno óptico: atração entre as sombras. Física na escola. v. 8, n.1, 2007.

BARION, Mariana Regina Lingiardi; SILVA, Heloísa Celis da; FERREIRA, Solange Gomes Colhado. A importância e os tipos das sombras utilizadas para bovinos a pasto. In: MOSTRA INTERNA DE TRABALHOS DE INICIAÇÃO CIENTÍFICA, 6., . Anais Eletrônico... [s.l.]: UniCesumar, 2012. Disponivel em: $<$ http://www.cesumar.br/prppge/pesquisa/mostras/vi_mostra/mariana_regina_lingiardi_barion .pdf>. Acesso em: 22 dez. 2017.

BAXANDALL, Michael. Sombras e luzes. São Paulo:EdUSP, 1997.

BELCHIOR, Elisabeth Morais. Importância da sombra nos espaços verdes de uma cidade transmontana: um caso de estudo. 2014. 48f. Dissertação (Mestrado em Gestão de Recursos Florestais) - Instituto Politécnico de Bragança, Bragança, 2014.

BÍBLIA de Jerusalém. São Paulo: Paulinas, 1980.

CARVALHO, M. M; XAVIER, D. F; ALVIM, M. J.; AROEIRA, L. J. Sistemas Silvipastoris: consórcio de árvores e pastagens. Viçosa-MG: [s. n.], 2002.

CASATI, Roberto. A descoberta da sombra: de Platāo a Galileu, a história de um enigma que fascina a humanidade. São Paulo: Companhia das letras, 2001.

CHOPRA, Deepak; FORD, Debbie; WILLIAMSON, Marianne. O efeito sombra. [S. 1]: Lua de Papel, 2010.

COSTA, Paranhos. M. J. R. e Cromberg, V. U. Alguns aspectos a serconsiderado para 
melhorar o bem estar de animais em sistema de pastejo rotacionado. In: PEIXOTO, A. M.; CRUZ, P. et al. Effects of shade on the growth and mineral nutrition of tropical grasses in silvopastoral systems. Annals of Arid Zone, v. 38, p. 335-361, 1999.

DIAS-FILHO, Moacyr Bernardino. Sistemas silvipastoris na recuperação de pastagens tropicais degradadas. In: GONZAGA Neto, S.; COSTA, R.G.; PIMENTA FILHO, E.C.; CASTRO, J.M. da C. (Eds.). SIMPÓSIOS DA REUNIÃO ANUAL DA SOCIEDADE BRASILEIRA DE ZOOTECNIA, 43. João Pessoa, Anais... João Pessoa: SBZ: UFPB, 2006 (Suplemento Especial da Revista Brasileira de Zootecnia, v.35, 2006). p. 535-553.

HAYASHIDE, Juliana Midori, et al. Doenças de pele entre trabalhadores rurais expostos a radiação solar. Estudo integrado entre as áreas de Medicina do trabalho e Dermatologia.

Revista Brasileira de Medicina do Trabalho, São Paulo-SP, v. 8, n. 2, p. 97-104, 2010. HEAD, H. H. Management of dairy cattle in tropical and subtropical. [S.l: s. n.], 1995. MEDEIROS, Jefferson Duate Barros de. Olhando a sombra através da utilização ritualística da bebida sagrada ayahuasca. Monografia (Especialização em Psicologia) FACIS, Junguiana, Brasília, 2016.

MIOT, Luciane Donida Bartoli; Hélio Amante Miot; Márcia Guimarães da Silva; Mariângela Esther Alencar Marques. Fisiopatologia do melisma. Anais Brasileiros de Dermatologia An. Bras. Dermatol. v.84, n.6, nov./ dez. 2009.

MUMFORD, Lewis. A cidade na história: suas origens, transformações e perpectivas. São Paulo: Martins Fontes, 1991.

OSMAN, Samira Adel; RIBEIRO, Olívia Cristina Ferreira. Arte, história, turismo e lazer nos cemitérios da cidade de São Paulo. Licere, Belo Horizonte, v. 10, n.1, p. 1-15, abr. 2007.

Disponível em: <http://www.anima.eefd.ufrj.br/licere/pdf/licereV10N01_a6.pdf>. Acesso em: 8 Novembro. 2016.

PEREIRA, Silvia Regina Mendes. Repercussões sócio-sanitárias da epidemia das fraturas de fêmur sobre a sobrevivência e a capacidade funcional do idoso. 2003. 164 f. Tese (Doutorado em Saúde Pública) - Fundação Oswaldo Cruz, Rio de Janeiro, 2003.

POPIM, Regina Célia, et al. Câncer de pele: uso de medidas preventivas e perfil demográfico de um grupo de risco na cidade de Botucatu. Ciência \& Saúde Coletiva, p. 1331-1336, 2008. PRIMAVESI, Ana Cândida, et al. Nutrientes na fitomassa de capim-marandu em função de fontes e doses de nitrogênio. Ciência e Agrotecnologia, v.30, n. 3, p. 562-568, 2006 a. PRIMAVESI, Ana. Manejo ecológico do solo: a agricultura em regiões tropicais. São Paulo: Ed. Nobel, 2006b.

RAGON, Michel. L'espace de la mort:essai sur l'architecture, la décoration et l'urbanisme funéraires. Paris: A. Michel, 1981.

SALETE, Mirian. A sombra não assombra: descubra sua luz interior. São Paulo: Butterfly, 2009.

STAFFORD-SMITH, D.M. et al. A heat balance model for sheep and its use to predict shade seeking behaviour in hot conditions. J. Appl. Ecol., v. 22, p. 753-774, 1985.

TOMÁS DE AQUINO. Compêndio de Teologia. São Paulo: Editora Abril, Cultural, 1979.

TREES instead of tombstones. Capsula Mundi, [2016?]. Disponível em:<

http://www.capsulamundi.it/en/>. Acesso em: 10 mar. 2017.

TUAN, Yu - Fu. Topofilia. São Paulo: Difel, 1980.

VALLADARES, Clarival do Prado. Arte e sociedade nos cemitérios brasileiros. Brasília: Imprensa Nacional, 1972.

VIOLLET-LE-DUC, Eugène Emmanuel. Dictionnaire raisonné de l'architecture française du XIe au XVIe siècle. Paris: A. Morel Éditions, 1867-1870. 
VOVELLE, Michel. L'heure du grand passage: chronique de la mort. Paris: Gallimard, 1993.

Recebido em 10 de agosto de 2018.

Aceito em 15 de setembro de 2018. 